\title{
Hydrogen Storage in Metal-Organic and Covalent-Organic Frameworks by Spillover
}

\author{
Yingwei Li and Ralph T. Yang \\ Dept. of Chemical Engineering, University of Michigan, Ann Arbor, MI 48109
}

DOI 10.1002/aic.11362

Published online November 12, 2007 in Wiley InterScience (www.interscience.wiley.com).

\begin{abstract}
Covalent-organic framework COF-1 and metal-organic frameworks HKUST-1 and MIL-101 were synthesized and studied for hydrogen storage at 77 and 298 K. Although MIL-101 had the largest surface area and pore volume among the three materials, HKUST-1 had the highest uptake $(2.28 \mathrm{wt} \%)$ at $77 \mathrm{~K}$. However, the $\mathrm{H}_{2}$ storage capacity at $298 \mathrm{~K}$ and high pressure correlated with the surface area and pore volume. The $\mathrm{H}_{2}$ storage in the COF and MOF materials assisted by hydrogen spillover, measured at $298 \mathrm{~K}$ up to a pressure of $10 \mathrm{MPa}$, have been examined for correlations with their structural and surface features for the first time. By using our simple technique to build carbon bridges, the hydrogen uptakes at $298 \mathrm{~K}$ were enhanced significantly by a factor of 2.6-3.2. The net uptake by spillover was correlated to the heat of adsorption through the Langmuir constant. Results on water vapor adsorption at $298 \mathrm{~K}$ indicated that COF-1 was unstable in moist air, while HKUST-1 and MIL-101 were stable. The results suggested that MIL-101 could be a promising material for hydrogen storage because of its high heat of adsorption for spiltover hydrogen, large surface area and pore volume, and stability upon $\mathrm{H}_{2} \mathrm{O}$ adsorption. (C) 2007 American Institute of Chemical Engineers AIChE J, 54: 269-279, 2008
\end{abstract}

Keywords: hydrogen storage, hydrogen spillover, covalent-organic framework, metalorganic framework, water vapor adsorption on $M O F$

\section{Introduction}

Hydrogen storage is of great interest as an enabler for using hydrogen as a possible substitute for fossil fuels for zero-emission energy technology. ${ }^{1}$ There are currently several candidate storage systems for hydrogen including liquid or high-pressure $\mathrm{H}_{2}$ gas, reversible metal hydrides, chemical hydrides, and porous adsorbents. However, up to date none is capable of satisfying the DOE criteria of size, recharge, kinetics, cost, and safety required for use in transportation., 2,3

Metal organic frameworks (MOFs) are a new class of porous materials with low density and high surface area. They are crystalline, infinite networks assembled by linking metal ions with various organic linkers through strong bonds. ${ }^{4}$ More recently, it was realized that some of them could be

Correspondence concerning this article should be addressed to R. T. Yang at yang@umich.edu.

(C) 2007 American Institute of Chemical Engineers promising candidates for hydrogen storage. ${ }^{5-26}$ In particular, MOF-177, a framework consisting of tetrahedral $\left[\mathrm{Zn}_{4} \mathrm{O}\right]^{6+}$ clusters linked by the tritopic link BTB (1,3,5-benzenetribenzoate), was demonstrated to adsorb reversibly up to $7.5 \mathrm{wt} \%$ $\mathrm{H}_{2}$ at $77 \mathrm{~K}$ and 70 bar. $^{27}$ However, most studies of $\mathrm{H}_{2}$ adsorption in MOFs were performed at very low temperatures (mostly at $77 \mathrm{~K}$ ). Few reports have showed that no significant hydrogen storages were obtained on the MOFs at room temperature. ${ }^{28}$ In addition, systematic studies on the effects of structural and surface properties, e.g., metal oxides, organic linking units, surface areas, and pore volumes, on the hydrogen storage capacities are scarce, especially at room temperature. $8,11,12,29-31$

Recently, we have shown that the hydrogen storage capacities at room temperature in metal-organic frameworks (IRMOF-1 and IRMOF-8) can be enhanced significantly by hydrogen spillover. ${ }^{32-35}$ By bridged spillover, the storage capacity in IRMOF-8 has been enhanced by a factor of up to 8 , to 2.2-4 wt $\%$ at $298 \mathrm{~K}$ and $10 \mathrm{MPa}$. There are several 
thousand MOFs already reported, but only very few of them have been studied for this purpose (i.e., hydrogen storage by spillover). A fundamental examination of the structure-property relationships of MOFs for hydrogen storage by spillover is needed. Through this undertaking, the structural and surface characteristics that most strongly influence the $\mathrm{H}_{2}$ adsorption capacity of MOFs by spillover may be elucidated and such results will provide a direction for future studies. We have begun such a systematic study on small subsets of MOFs and related materials.

For practical applications of hydrogen storage, the storage material should be rechargeable. $\mathrm{H}_{2} \mathrm{O}$ is very difficult to be fully removed from commercial hydrogen sources. For practical applications, it is not economical to use super-highpurity hydrogen for transportation because of the additional cost for purifying hydrogen. Thus, the $\mathrm{H}_{2} \mathrm{O}$ adsorption characteristics and the structure stability upon $\mathrm{H}_{2} \mathrm{O}$ adsorption are very important issues for a promising hydrogen storage material for practical applications. ${ }^{36}$ This is even more problematic for MOFs because MOFs decompose easily at elevated temperatures, indicating the instability of this type of material. Recently, Panella and Hirscher observed a different X-ray diffraction pattern on the MOF-5 (a.k.a. IRMOF-1) sample after exposing the sample in air for 6 weeks, indicating that MOF-5 tends to decompose in air. ${ }^{37}$ Huang et al. also observed a similar phenomenon on MOF-5 when stirring the sample in water for $0.5 \mathrm{~h}$. These results indicate that MOFs could be unstable upon $\mathrm{H}_{2} \mathrm{O}$ adsorption. ${ }^{38}$

Here we report experimental data on hydrogen storage in three recently reported covalent-, or metal-organic frameworks (COF-1, HKUST-1, and MIL-101). These materials were selected for this work because they could be candidate materials for hydrogen storage. Covalent organic frameworks (COFs) are constructed from light elements $(\mathrm{H}, \mathrm{B}, \mathrm{C}, \mathrm{N}$, and O) that form strong covalent bonds. ${ }^{39}$ Therefore they have very light weights and exceptional thermal stabilities (to temperatures up to $600^{\circ} \mathrm{C}$ ) that could be suitable for gas storage. HKUST-1 is a copper benzene tricarboxylate porous material that was first reported by Williams and coworkers. ${ }^{40}$ Recent research showed that it is an excellent material for gas storage, such as for $\mathrm{H}_{2}$ and NO. ${ }^{41}$ The high gas capacities in the HKUST-1 may be due to the presence of a metal site in the walls of the material that could interact strongly with a gas molecule. ${ }^{26}$ MIL-101 is constructed from benzene-1,4-dicarboxylate and trimetric chromium (III) octahedral cluster which have very large pore size $(\sim 30$ to $34 \AA)$ and surface area (Langmuir surface area, 4500-5500 $\mathrm{m}^{2} / \mathrm{g}$ ). ${ }^{16}$ It was reported that the hydrogen storage capacities in this material at $8 \mathrm{MPa}$ was $6.1 \mathrm{wt} \%$ at $77 \mathrm{~K}$, and $0.43 \mathrm{wt} \%$ at $298 \mathrm{~K}$, respectively. ${ }^{28}$ HKUST-1 and MIL-101 were synthesized in the presence of $\mathrm{H}_{2} \mathrm{O}$, so their structures should be stable upon water adsorption. In this article, these materials were synthesized according to the published procedures and characterized by powder Xray diffraction, infrared spectroscopy, SEM, TGA, and $\mathrm{N}_{2}$ adsorption at $77 \mathrm{~K}$. Water vapor adsorption isotherms and structure stabilities of the materials upon $\mathrm{H}_{2} \mathrm{O}$ adsorption were studied. Hydrogen adsorption isotherms were measured at $77 \mathrm{~K}$ up to $1 \mathrm{~atm}$, and $298 \mathrm{~K}$ up to $100 \mathrm{~atm}$, respectively. Hydrogen storage by spillover was also examined on these materials. Carbon bridges were built in the materials by carbonization of sucrose to enhance the spillover. ${ }^{32,34,42}$ In com- paring their dihydrogen adsorption isotherms and net hydrogen storage capacities by spillover, correlations with their structural and surface features are discussed.

\section{Experimental Methods}

\section{Preparation of COF-1, HKUST-1, and MIL-101}

$\mathrm{COF}-1, \mathrm{C}_{3} \mathrm{H}_{2} \mathrm{BO}$. COF-1 was synthesized according to the reported procedures, ${ }^{39}$ albeit in a larger scale for this study. Typically, $100 \mathrm{mg}$ 1,4-benzene diboronic acid (BDBA) was loaded into a Pyrex glass tube (i.d. $=16 \mathrm{~mm}$ ). The diameter of the tube was two times larger than that used by Cote et al. (i.d. $=8 \mathrm{~mm}$ ) because four times more raw materials were used in this work. About $4 \mathrm{~mL}$ of $1: 1$ (volumetric ratio) solution of mesitylene:dioxane was added. The tube was connected to a Micromeritics ASAP 2010 sorptometer degassing port, flash frozen with a liquid nitrogen bath. It was evacuated to an internal pressure of $\sim 150 \mu \mathrm{m} \mathrm{Hg}$, and then flame-sealed. Upon sealing the length of the tube was reduced to $\sim 18 \mathrm{~cm}$. The tube was heated to $120^{\circ} \mathrm{C}$ in an oven and held at this temperature for $72 \mathrm{~h}$. The white product was collected by repeated filtering and thorough washing with acetone. The sample was dried in an oven at $60^{\circ} \mathrm{C}$ for $0.5 \mathrm{~h}$, and then degassed in vacuum at $150^{\circ} \mathrm{C}$ for $12 \mathrm{~h}$ before measurements.

HKUST-1, $\mathrm{Cu}_{2}\left(\mathrm{C}_{9} \mathrm{H}_{3} \mathrm{O}_{6}\right)_{4 / 3}$. In a typical synthesis, benzene-1,3,5-tricarboxylic acid (5 g, $24 \mathrm{mmol})$ was heated with copper nitrate hemipentahydrate $(10 \mathrm{~g}, 43 \mathrm{mmol})$ in $250 \mathrm{~mL}$ of solvent consisting of equal parts of $N, N$-dimethylformamide (DMF), ethanol, and deionized water in a $1-\mathrm{L}$ wide mouth glass jar. ${ }^{29,40}$ The jar was tightly capped and placed in an oven at $85^{\circ} \mathrm{C}$ for $20 \mathrm{~h}$. The product was isolated by filtration and washing with $\mathrm{DMF}$, and then dried at $60^{\circ} \mathrm{C}$ for $1 \mathrm{~h}$. The solvent was removed by degassing in vacuum at $180^{\circ} \mathrm{C}$ for $6 \mathrm{~h}$, yielding the porous material.

MIL-101, $\quad \mathrm{Cr}_{3} \mathrm{~F}\left(\mathrm{H}_{2} \mathrm{O}\right)_{2} \mathrm{O}\left[\left(\mathrm{O}_{2} \mathrm{C}\right)-\mathrm{C}_{6} \mathrm{H}_{4}-\left(\mathrm{CO}_{2}\right)\right]_{3} \cdot n \mathrm{H}_{2} \mathrm{O}$. In this study, five times more starting materials were used for the synthesis of MIL-101 than that described in the literature because we used a larger bomb in our synthesis. ${ }^{16}$ $\mathrm{Cr}\left(\mathrm{NO}_{3}\right)_{3} \cdot 9 \mathrm{H}_{2} \mathrm{O}(2.0 \mathrm{~g}, 5 \mathrm{mmol})$, fluorhydric acid (48 wt \%, $5 \mathrm{mmol})$, and 1,4-benzene dicarboxylic acid (0.82 g, $5 \mathrm{mmol}$ ) were dissolved in $24 \mathrm{~mL}$ deionized water. The mixture was introduced in a $300 \mathrm{~mL}$ hydrothermal bomb which was heated to $220^{\circ} \mathrm{C}$ at a heating rate of $1^{\circ} \mathrm{C} / \mathrm{min}$. The temperature was held at $220^{\circ} \mathrm{C}$ for $8 \mathrm{~h}$, cooled first to $150^{\circ} \mathrm{C}$ in $1 \mathrm{~h}$, and then slowly to room temperature in $12 \mathrm{~h}$. Upon the slow cooling procedure, most of the residual carboxylic acid was in large crystals that can be easily isolated from the solution and MIL-101 powder by using a large pore fritted glass filter ( $n^{\circ} 2$, Schott). The free terephthalic acid was eliminated and the green MIL-101 powder was separated from the solution using a small pore paper filter ( $1^{\circ}$, Whatman). The powder was washed thoroughly with deionized water and ethanol, and then dried in a $60^{\circ} \mathrm{C}$ oven. The material was degassed in vacuum at $100^{\circ} \mathrm{C}$ for $12 \mathrm{~h}$, cooled down to room temperature and stored under vacuum.

\section{Preparation of bridged samples}

An effective bridge building technique has been developed and described in detail in our previous publication. ${ }^{32,34,42,43}$ 
A catalyst containing $5 \mathrm{wt} \%$ platinum supported on active carbon (Pt/AC, Strem Chemicals) was used as the source for hydrogen dissociation. Active carbon can be considered as the primary receptor for hydrogen atoms. Here COF-1, HKUST-1, or MIL-101 was the secondary spillover receptor. Carbon bridges between the source and receptor were formed by carbonization of sucrose that was previously introduced into a physical mixture of the two components. The receptor/ bridge-precursor/source ratio was fixed at 8:1:1 based on the complete carbonization of the precursor. The ternary mixture was ground together for $1 \mathrm{~h}$, and then subjected to the heat treatment procedures as described in the previous paper for preparing the bridged IRMOF- 8 sample. ${ }^{34}$ The formation of carbon bridges by using the bridge building technique has been confirmed by HRTEM. ${ }^{42}$

\section{Characterization}

Powder X-ray diffraction (XRD) patterns were collected on a Rigaku Miniflex diffractometer at $30 \mathrm{kV}, 15 \mathrm{~mA}$ for $\mathrm{Cu}$ $\mathrm{K} \alpha(\lambda=0.1543 \mathrm{~nm})$ radiation, with a scan speed of $2 \% \mathrm{~min}$ and a step size of $0.02^{\circ}$ in $2 \theta$. Infrared spectra (IR) were recorded on a Nicolet Impact 400 FTIR spectrometer with a TGS detector. Scanning electron microscopy (SEM) images were obtained on a Philips XL 30 FEG SEM instrument equipped with UTW Si-Li solid state X-ray detector (XEDS) using a $15 \mathrm{kV}$ accelerating voltage. Thermogravimetric analysis (TGA) of samples was performed on a TGA-50 thermogravimetric analyzer (Shimadzu) using a constant heating rate of $5^{\circ} \mathrm{C} / \mathrm{min}$ under $\mathrm{He}$ atmosphere. Brunauer-EmmettTeller (BET) surface areas and pore volumes were measured on a Micromeritics ASAP 2020 sorptometer using nitrogen adsorption at $77 \mathrm{~K}$.

\section{Hydrogen isotherm measurements}

Low-pressure $\mathrm{H}_{2}$ adsorption isotherms at 77 or $298 \mathrm{~K}$ were measured with a standard static volumetric technique (Micromeritics ASAP 2020). Approximately $200 \mathrm{mg}$ of sample was used for each measurement. Samples were degassed in vacuum at $150^{\circ} \mathrm{C}$ for at least $12 \mathrm{~h}$ prior to measurements to remove any residual guest molecules to obtain the highest gas adsorption capacity.

Hydrogen adsorption at $298 \mathrm{~K}$ and pressures greater than $0.1 \mathrm{MPa}$ and up to $10 \mathrm{MPa}$ was measured using a static volumetric technique with a specially designed Sievert's apparatus. The apparatus was previously tested to prove to be leakfree and proven for accuracy through calibration by using $\mathrm{LaNi}_{5}$, AX-21, zeolites, and IRMOFs at $298 \mathrm{~K}$. All isotherms matched the known values. Typically, $200 \mathrm{mg}$ of sample was used for each high-pressure isotherm measurement. Prior to measurements, the samples were degassed in vacuum at $200^{\circ} \mathrm{C}$ for at least $12 \mathrm{~h}$.

\section{Results and Discussion Characterization results}

Powder XRD patterns for COF-1, HKUST-1, and MIL-101 are shown in Figure 1. All samples showed good crystallinity. The diffraction peaks of each sample prepared in this study matched well with the already published XRD patterns on the same COF or MOF. ${ }^{16,29,39,44}$ Figure 2 shows the IR spectra of the COF-1, HKUST-1, and MIL-101 samples. As shown in Figure 2a, the vibrational bands around 1376 and $1340 \mathrm{~cm}^{-1}$ can be assigned to $\mathrm{B}-\mathrm{O}$ stretch (characteristic bands for boroxine). ${ }^{39}$ The presence of $\mathrm{B}-\mathrm{C}$ bonds and the $\mathrm{B}_{3} \mathrm{O}_{3}$ ring units in the synthesized material was indicated by the bands around 1023 and $708 \mathrm{~cm}^{-1}$, respectively. Thus, the agreement of the vibrational bands found in Figure 2a on our sample with the literature data on COF-1 confirmed the presence of COF-1 structure in our sample. All the vibrational bands shown in Figure $2 b$ are in good agreement with the published data on HKUST-1. ${ }^{29,40}$ Figure 2c shows the IR spectra of the synthesized MIL-101 sample. The presence of the bands characteristic of the framework $-(\mathrm{O}-\mathrm{C}-\mathrm{O})-$ groups around 1539 and $1425 \mathrm{~cm}^{-1}$ indicated the presence of the dicarboxylate within MIL-101. ${ }^{16}$ The broad bands around $1620 \mathrm{~cm}^{-1}$ indicated that a large amount of water molecules were present in the sample.

The SEM images of the COF-1, HKUST-1, and MIL-101 materials are shown in Figure 3. It can be seen that only one
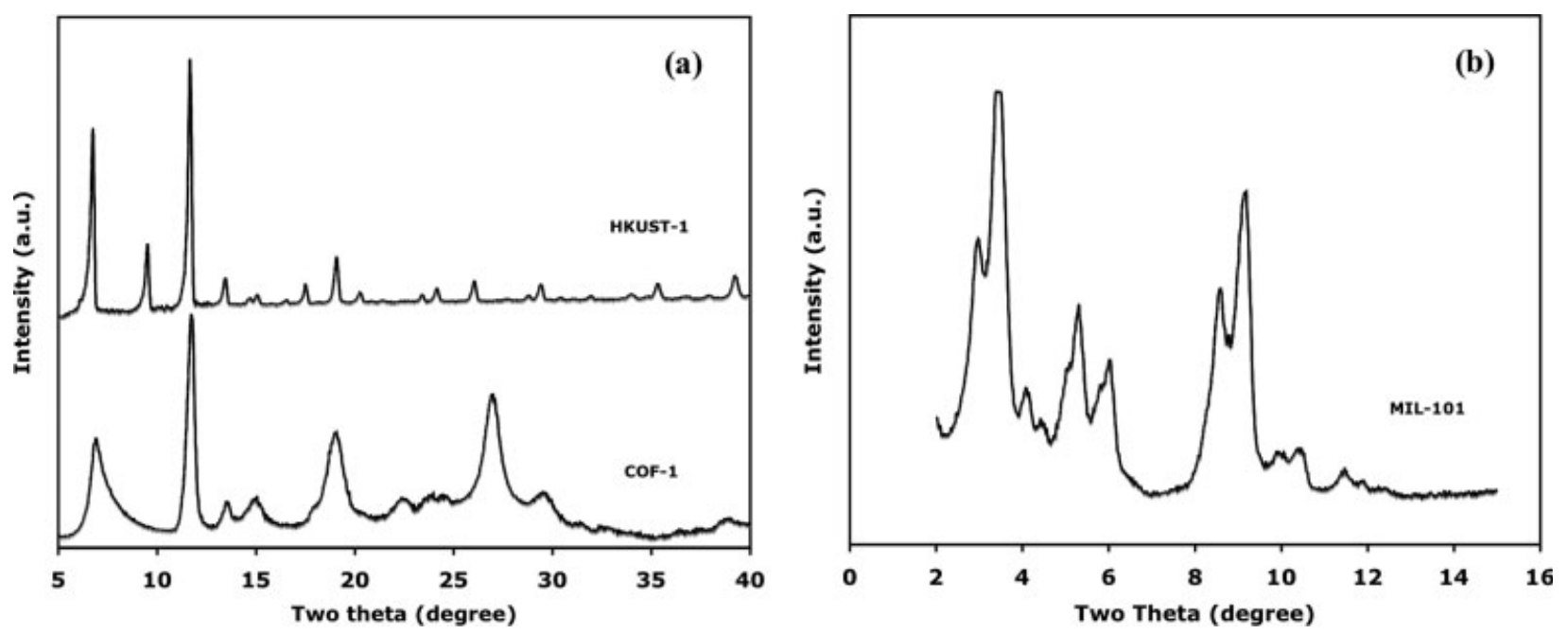

Figure 1. X-ray diffraction patterns of (a) COF-1, HKUST-1, and (b) MIL-101. 

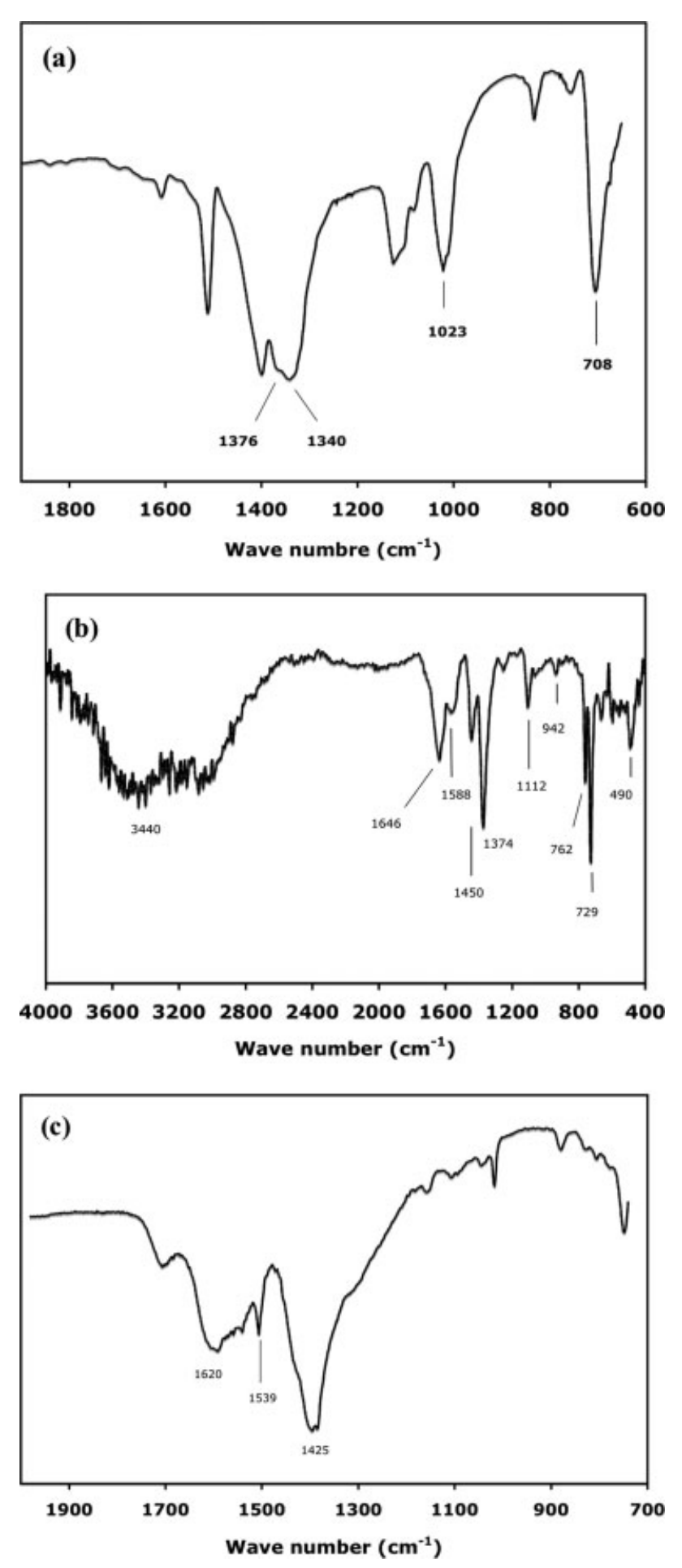

Figure 2. Infra-red spectra of COF-1 (a), HKUST-1 (b), and MIL-101 (c).

unique morphology of crystallite was found for each material, confirming the phase purity of the samples. The uniform sizes of the COF-1 and MIL-101 particles were around 0.3$0.4 \mu \mathrm{m}$ for COF-1 and $0.2-0.3 \mu \mathrm{m}$ for MIL-101, respectively. HKUST-1 crystallized in double-sided pyramids with a size of 4-8 $\mu \mathrm{m}$. Besides these small crystals, bigger crystals with sizes of 13-18 $\mu \mathrm{m}$ were also found. Similar morphology of the crystals (i.e., double-sided pyramids) was also observed on the $\mathrm{Cu}$-containing MOF (Cu-BTC). ${ }^{31,45}$

Figure 4 shows the TGA curves of the COF-1, HKUST-1, and MIL-101 samples upon heating in He. COF-1 exhibited very high thermal stability (to temperatures up to 550$600^{\circ} \mathrm{C}$ ). HKUST-1 and MIL-101 were less stable, with decomposition temperatures around $290^{\circ} \mathrm{C}$ for HKUST- 1 and $310^{\circ} \mathrm{C}$ for MIL-101. It should be noted that the carbonization temperature for building carbon bridges in these materials was all $250^{\circ} \mathrm{C}$, which was well below the decomposition temperatures of these materials. Thus the framework structures of the materials should be stable upon the bridge building procedure.

The BET surface areas and pore volumes of the materials measured by $\mathrm{N}_{2}$ adsorption at $77 \mathrm{~K}$ are shown in Table 1 . The BET surface area of COF-1 was $628 \mathrm{~m}^{2} / \mathrm{g}$, slightly lower than that reported by Yaghi and coworkers $\left(711 \mathrm{~m}^{2} / \mathrm{g}\right) .{ }^{39}$ But the pore volume of $0.36 \mathrm{~cm}^{3} / \mathrm{g}$ was slightly higher than the reported value $\left(0.32 \mathrm{~cm}^{3} / \mathrm{g}\right)$. The BET surface area and pore volume of HKUST-1 were very close to that reported by Rowsell and Yaghi, ${ }^{29}$ while much higher than the values obtained by Chui et al. ${ }^{40}$ and Lee et al. ${ }^{46}$ The BET surface area and pore volume of the MIL-101 sample were $2931 \mathrm{~m}^{2} / \mathrm{g}$ (Langmuir S.A., $4300 \mathrm{~m}^{2} / \mathrm{g}$ ) and $1.45 \mathrm{~cm}^{3} / \mathrm{g}$, respectively. These values were in good agreement with those reported by Ferey and coworkers. ${ }^{16,28}$

The BET surface areas of the bridged samples were measured as $582 \mathrm{~m}^{2} / \mathrm{g}$ for bridged COF-1, $1116 \mathrm{~m}^{2} / \mathrm{g}$ for bridged HKUST-1, and $2580 \mathrm{~m}^{2} / \mathrm{g}$ for bridged MIL-101, respectively. No significant differences were observed between the bridged samples and the corresponding pure COF or MOF materials. The slight decreases in the surface areas upon bridge building can be attributed to the low surface areas of the carbon bridges ( $\sim 10 \mathrm{wt} \%$ in the samples) from carbonization of sucrose. Furthermore, XRD patterns of the bridged IRMOF-8 and the pure IRMOF-8 were essentially identical. ${ }^{34}$ These results confirmed the structure stabilities of the materials to the bridge building procedure.

\section{$\mathrm{H}_{2} \mathrm{O}$ adsorption isotherm and material stability studies}

The adsorption isotherms of $\mathrm{H}_{2} \mathrm{O}$ vapor at $298 \mathrm{~K}$ on the COF-1, HKUST-1, and MIL-101 samples are shown in Figure 5. It was observed that HKUST-1 and MIL-101 had much higher $\mathrm{H}_{2} \mathrm{O}$ adsorption capacities than COF-1. The $\mathrm{H}_{2} \mathrm{O}$ adsorption amounts on the COF-1, HKUST-1, and MIL101 samples at $P / P_{0}>0.5$ were $5.3,28.0$, and 42.8 wt $\%$, respectively. The $\mathrm{H}_{2} \mathrm{O}$ uptakes on the HKUST-1 and MIL101 samples agreed well with the published TGA weight loss results on HKUST-1 $(\sim 28.2 \mathrm{wt} \%)$ and MIL-101 $\left(\sim 40\right.$ wt \%). ${ }^{16,40}$ The much higher $\mathrm{H}_{2} \mathrm{O}$ capacities on HKUST-1 and MIL-101 than COF-1 can be attributed to the higher pore volumes and the metal-oxide clusters present in the frameworks of HKUST-1 and MIL-101. COF-1 is more hydrophobic because there is no metal-oxide cluster unit in the framework structure. As can be seen from Figure 5, the desorption of $\mathrm{H}_{2} \mathrm{O}$ did not totally follow the adsorption branch for all the samples at $298 \mathrm{~K}$. This indicated that the adsorption of $\mathrm{H}_{2} \mathrm{O}$ was not completely reversible at $298 \mathrm{~K}$ on the $\mathrm{COF}$ or MOF material. 

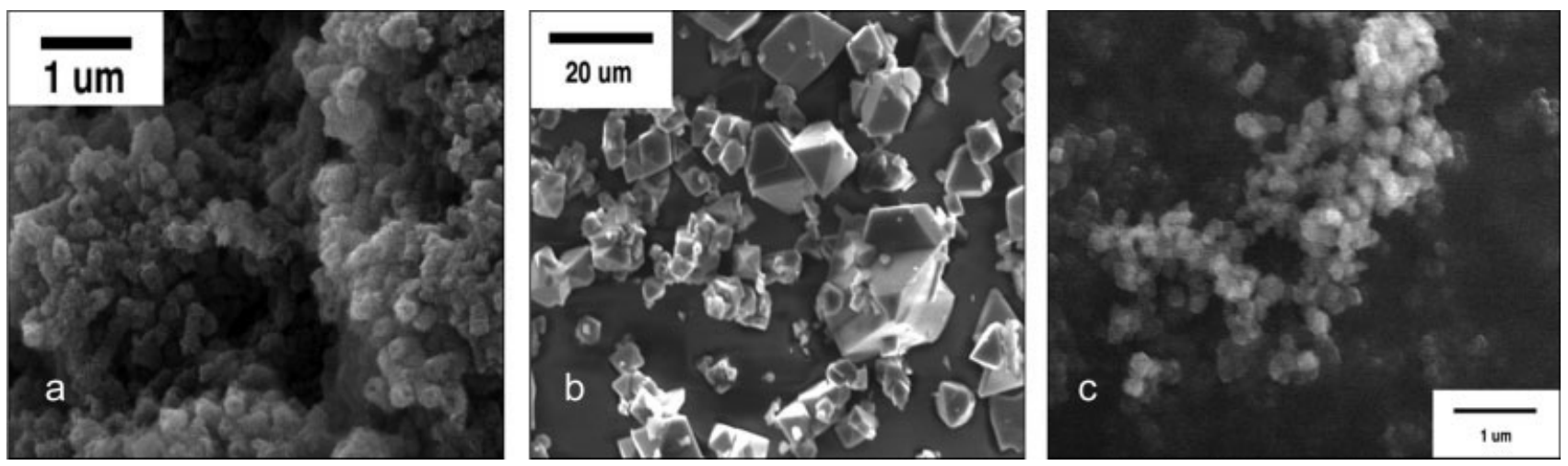

Figure 3. SEM images of COF-1 (a), HKUST-1 (b), and MIL-101 (c).

The adsorbed $\mathrm{H}_{2} \mathrm{O}$ on the samples would have a significant effect on the COF or MOF structure if the $\mathrm{H}_{2} \mathrm{O}$ is not desorbed immediately. For practical hydrogen applications for personal automobiles, the period between two refills would be normally several days. Thus studies on the structure stabilities of hydrogen storage materials with $\mathrm{H}_{2} \mathrm{O}$ present are important for potential applications. In this study, the stabilities of the COF-1, HKUST-1, and MIL-101 materials were investigated by exposing the samples in ambient air for 7 days (i.e., in air-conditioned room with a relative humidity $\sim 40 \%$, at $298 \mathrm{~K}$ ). The XRD patterns of the exposed samples are compared with that of the as-synthesized samples. The plots are presented in Figure 6. It was found from Figure 6a that the COF-1 sample after exposing to air at room temperature exhibited a mixed XRD pattern of the COF-1 and BDBA (i.e., the starting material for COF-1). The characteristic peak for COF-1 at $2 \theta \sim 7^{\circ}$ was reduced markedly. This revealed that the COF-1 structure was decomposing into BDBA with $\mathrm{H}_{2} \mathrm{O}$ adsorbed from the ambient air at $298 \mathrm{~K}$. Whereas no significant difference was observed between the exposed sample and the as-synthesized one for both HKUST1 and MIL-101, as shown in Figures 6c, d. The results indicated the stabilities of the HKUST-1 and MIL-101 materials upon water adsorption at room temperature, as also confirmed by $\mathrm{N}_{2}$ adsorption at $77 \mathrm{~K}$. The BET surface areas and pore volumes of the exposed samples after degassing in vacuum at $120^{\circ} \mathrm{C}$ for $12 \mathrm{~h}$ are summarized in Table 1 . Almost the same surface areas and pore volumes were obtained between the ambient-air-aged and the as-synthesized samples for both HKUST-1 and MIL-101. However, the data were greatly reduced after exposing the COF-1 sample in air for 7 days, as can be seen from Table 1 .

\section{$\mathrm{H}_{2}$ adsorption studies}

Hydrogen adsorption isotherms of the materials at $77 \mathrm{~K}$ and at pressures up to $1 \mathrm{~atm}$ are presented in Figure 7 . It can be seen that the $\mathrm{H}_{2}$ adsorption on all samples showed a reversible Type I isotherm characteristic of a microporous material. The $\mathrm{H}_{2}$ uptakes at 1 atm and $77 \mathrm{~K}$ are given in Table 1. The reported values of hydrogen adsorption on HKUST-1 at $77 \mathrm{~K}$ and $1 \mathrm{~atm}$ vary quite substantially. Yaghi and coworkers reported a value of $2.5 \mathrm{wt} \%$ in one paper while $1.6 \mathrm{wt} \%$ in another at $77 \mathrm{~K}$ and $1 \mathrm{~atm}^{27,29} \mathrm{Xiao}$ et al. ${ }^{41}$ reported a high $\mathrm{H}_{2}$ uptake of 2.27 wt $\%$, but Lee et al. ${ }^{46}$ and Prestipino et al. ${ }^{26}$ both reported a much lower $\mathrm{H}_{2}$ capacity of $1.25 \mathrm{wt} \%$ under the same conditions. In the present work, the highest $\mathrm{H}_{2}$ capacity at 1 atm and $77 \mathrm{~K}$ was measured as 2.28 wt $\%$ on the HKUST-1 material, almost the same as that reported by Xiao et al. ${ }^{41}$ The large range of the $\mathrm{H}_{2}$ uptake for HKUST-1 could be attributed to the sample purity. ${ }^{41}$ The guest molecules in the frameworks must be fully removed to obtain the highest gas adsorption capacity. The calculated crystallographic pore volume from PLATON is $\sim 0.72 \mathrm{~cm}^{3} / \mathrm{g} .{ }^{41}$ Good agreement between the calculated pore volume and that obtained from $\mathrm{N}_{2}$ adsorption in this study confirms the purity of our sample. The similar pore volumes reported in Xiao's paper as in this study can account for the same $\mathrm{H}_{2}$ uptake obtained on the HKUST-1 samples.

Ferey and coworkers measured the hydrogen isotherms of MIL-101 at $77 \mathrm{~K}$ up to $8 \mathrm{MPa}^{28}$ The first measurement showed an uptake of $4.5 \mathrm{wt} \%$ at $77 \mathrm{~K}$ and $3 \mathrm{MPa}$ after correction. ${ }^{47}$ In a second publication, a high uptake of $6.1 \mathrm{wt} \%$ at $8 \mathrm{MPa}(5.5 \mathrm{wt} \%$ at $3 \mathrm{MPa})$ was reported on the MIL$101 \mathrm{~b}$ material with additional activation treatments. On the MIL-101a sample obtained in the same synthesis conditions as MIL-101b but without additional activation, the $\mathrm{H}_{2}$ uptake was $\sim 4.3 \mathrm{wt} \%$ with a saturation plateau above $4 \mathrm{MPa}^{28}$

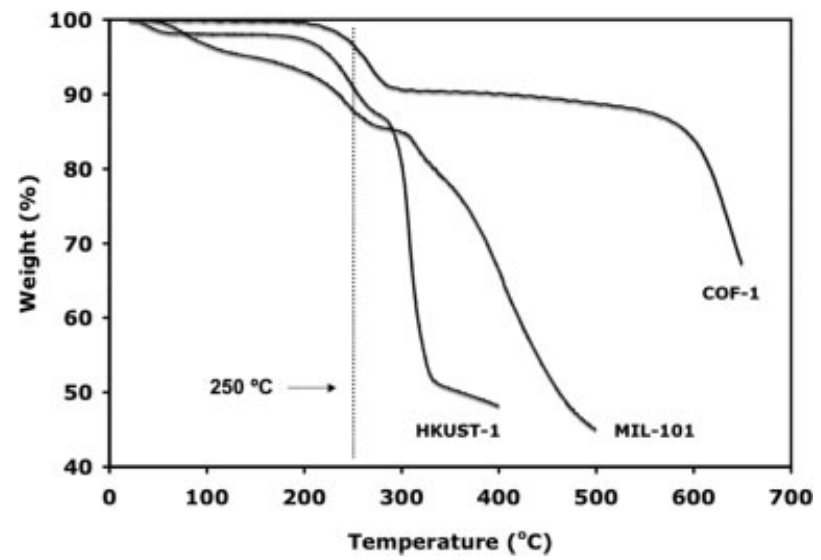

Figure 4. TGA curves for COF-1, HKUST-1, and MIL101 under helium atmosphere. 
Table 1. BET Surface Area, Pore Volume, and $\mathrm{H}_{2}$ Uptake of the COF-1, HKUST-1, and MIL-101 Materials

\begin{tabular}{lcccc}
\hline & BET Surface & Pore Volume \\
$\left(\mathrm{cm}^{3} / \mathrm{g}\right)^{*}$ & Area $\left(\mathrm{m}^{2} / \mathrm{g}\right)$ & $\begin{array}{c}\mathrm{H}_{2} \text { Uptake at } \\
77 \mathrm{~K} \text { and } \\
1 \mathrm{~atm}(\mathrm{wt} \%)\end{array}$ & $\begin{array}{c}\mathrm{H}_{2} \text { Uptake at } \\
298 \mathrm{~K} \text { and }\end{array}$ & $\begin{array}{c}1.28 \\
10 \mathrm{MPa}(\mathrm{wt} \%)\end{array}$ \\
\hline COF-1 & $628(50)^{\dagger}$ & $0.36(0.03)^{\dagger}$ & 2.28 & 0.26 \\
HKUST-1 & $1296(1289)$ & $0.69(0.69)$ & 1.91 & 0.35 \\
MIL-101 & $2931(3023)$ & $1.45(1.48)$ & 0.51 \\
\hline
\end{tabular}

*From BJH analysis.

${ }^{\dagger}$ The data in the parentheses represent the surface areas or pore volumes of the samples after exposing to air (relative humidity $\sim 40 \%, 298 \mathrm{~K}$ ) for 7 days.

The $\mathrm{H}_{2}$ adsorption capacity at $77 \mathrm{~K}$ and 1 atm was measured as $1.91 \mathrm{wt} \%$ on the MIL-101 sample prepared in this study, as shown in Figure 7. This value is very close to the estimated $\mathrm{H}_{2}$ uptakes on the MIL-101a and MIL-101b samples from the reported $\mathrm{H}_{2}$ isotherms at $77 \mathrm{~K}$ up to $8 \mathrm{MPa}^{28}$ Frost et al. investigated the effects of surface area, free volume, and heat of adsorption on the hydrogen uptake in MOFs at $77 \mathrm{~K}$ using Monte Carlo simulations. ${ }^{8}$ It was suggested that at low pressures the $\mathrm{H}_{2}$ uptake correlated with the heat of adsorption of $\mathrm{H}_{2}$ on the MOFs. Therefore, no significant difference was observed on the $\mathrm{H}_{2}$ uptakes at 1 atm and $77 \mathrm{~K}$ between our sample, MIL-101a and MIL-101b, although MIL-101b had higher Langmuir surface area $\left(\sim 5500 \mathrm{~m}^{2} / \mathrm{g}\right)$ than our sample and the MIL-101a without additional activation.

Since the first synthesis of COF-1 by Yaghi et al., there is no report on the $\mathrm{H}_{2}$ adsorption study on this new material. ${ }^{39}$ As shown in Figure 7, the $\mathrm{H}_{2}$ uptake at $77 \mathrm{~K}$ and 1 atm was measured as 1.28 wt $\%$ on the COF-1 sample prepared in this study. Although this value was much lower than the other two MOFs studied in this article, it can still be comparable with the $\mathrm{H}_{2}$ uptakes on some IRMOFs with much higher surface areas, such as IRMOF-1 and IRMOF-8. ${ }^{12}$

High-pressure hydrogen adsorption isotherms at $298 \mathrm{~K}$ for the COF-1, HKUST-1, and MIL-101 samples are presented in Figures $8-10$. The $\mathrm{H}_{2}$ storage capacities of the materials at $10 \mathrm{MPa}$ are summarized in Table 1 . The highest hydrogen uptake of $0.51 \mathrm{wt} \%$ was obtained on the MIL-101 material. The adsorption amount at $8 \mathrm{MPa}$ was measured as $0.41 \mathrm{wt} \%$, which agrees well with that reported by Ferey and coworkers under the same conditions. ${ }^{28} \mathrm{COF}-1$ exhibited the lowest adsorption capacity among the three materials at $298 \mathrm{~K}$ and $10 \mathrm{MPa}$, as can be seen from Table 1 . This can be attributed to the much lower BET surface area and pore volume of COF-1 than that of the other two materials. Although HKUST-1 had the highest $\mathrm{H}_{2}$ uptake of 2.28 wt $\%$ at $77 \mathrm{~K}$ and $1 \mathrm{~atm}$, the $\mathrm{H}_{2}$ storage capacity at high pressures and $298 \mathrm{~K}$ was much lower than MIL-101. These data suggested that at room temperature and very high pressures (close to saturation adsorption) the $\mathrm{H}_{2}$ uptake would correlate with the surface area and/or the pore volume of the material.

It can be seen from Figures $8-10$ that by simply mixing the COF or MOF material with a small amount of Pt/AC catalyst (at 9:1 mass ratio), the hydrogen uptakes have been significantly enhanced at all pressures up to $10 \mathrm{MPa}$. The $\mathrm{H}_{2}$ adsorption capacities were further enhanced by creating physical carbon "bridges" between the COF or MOF material and the Pt/AC catalyst to increase the contacts of the two unlike materials and hence facilitate secondary spillover.
In comparison with the pure material without spillover, it can be seen that the hydrogen storage capacity has been enhanced by a factor of 2.6 for COF-1, 3.2 for HKUST-1, and 2.8 for MIL-101, respectively. Another interesting feature was that there was no apparent saturation value for the bridged samples, as shown in Figures 8-10. In addition, the adsorption in the bridged samples was fully reversible at $298 \mathrm{~K}$, as found previously on the bridged IRMOFs, zeolites, and carbon materials. ${ }^{34,42,43}$

It has been observed by many authors that the hydrogen uptake at $77 \mathrm{~K}$ and elevated pressures correlates with the pore volume of the material. This can be easily understood because at very high pressures the storage is mainly by condensation of $\mathrm{H}_{2}$ molecules in the pores of the material. However, in the storage system by spillover, hydrogen molecules are initially dissociated on metal nanoparticles, and subsequently hydrogen atoms migrate onto the surface of the receptor by spillover and surface diffusion. ${ }^{48}$ That is, the adsorption by spillover is the interaction of hydrogen atoms with the surface sites of the material. Therefore, the pore volume of the material should not be the key factor in the net hydrogen storage capacity by spillover. Several papers have reported a linear correlation between the saturation $\mathrm{H}_{2}$ uptake and the surface area of MOFs at $77 \mathrm{~K} .{ }^{8,27,31}$ However, such a linear correlation between the net adsorption capacity by

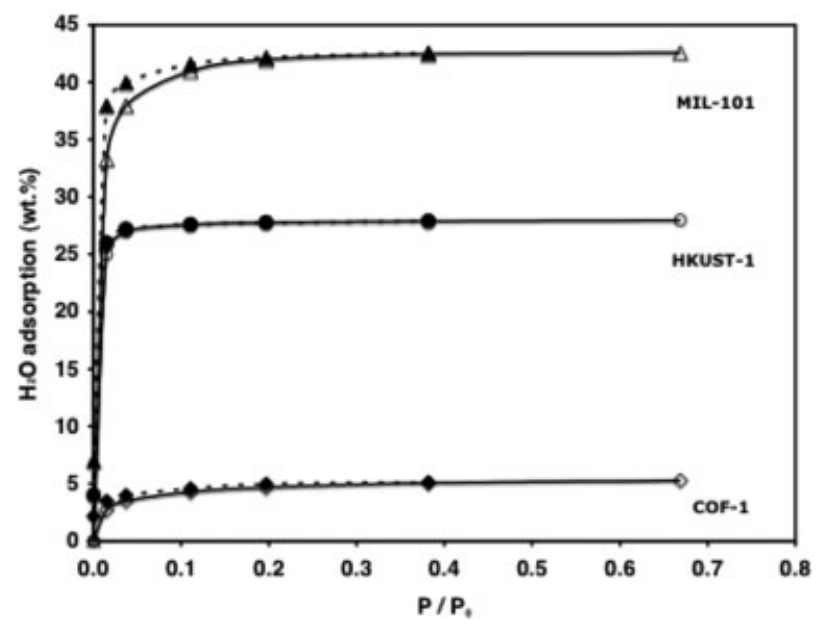

Figure 5. $\mathrm{H}_{2} \mathrm{O}$ adsorption isotherms at $298 \mathrm{~K}$ for the COF-1, HKUST-1, and MIL-101 samples.

$P / P_{0}$ is the ratio of $\mathrm{H}_{2} \mathrm{O}$ vapor pressure $(P)$ to saturation pressure of $\mathrm{H}_{2} \mathrm{O}$ at $298 \mathrm{~K}\left(P_{0}\right)$. Filled symbols indicate the desorption branches. 

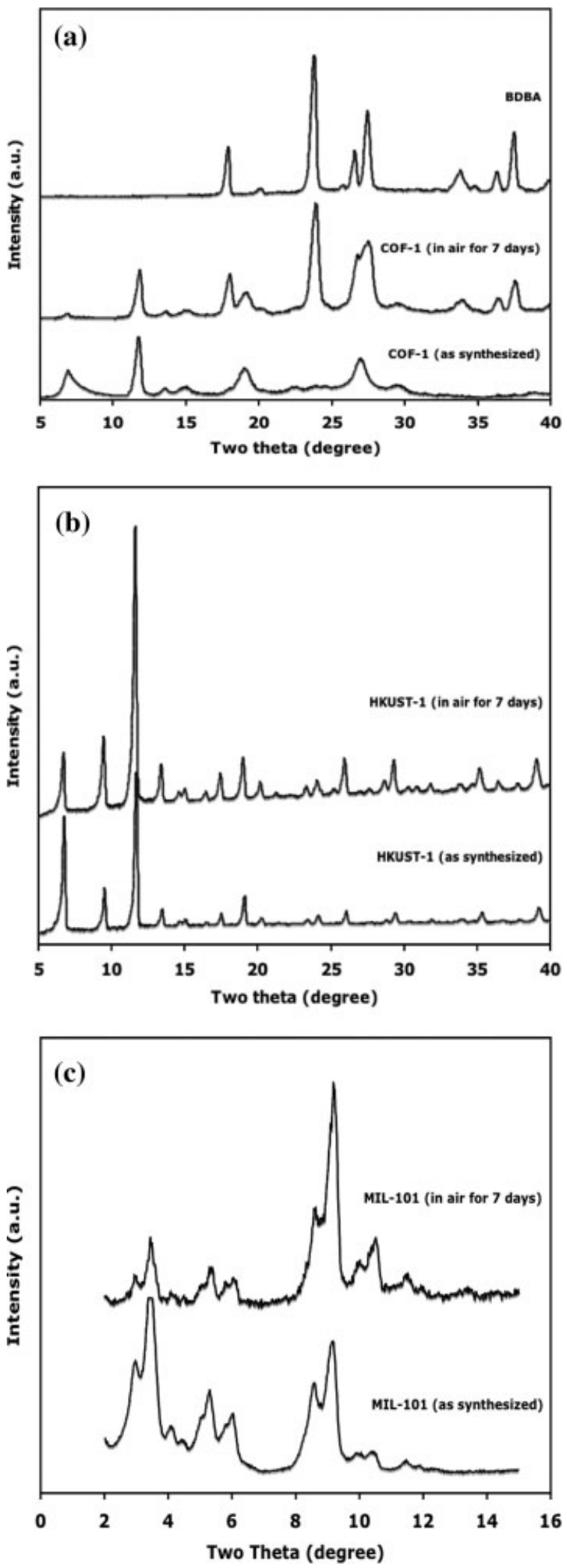

Figure 6. XRD patterns of COF-1 (a), HKUST-1 (b), and MIL-101 (c) after exposing in air for 7 days.

spillover and the surface area was not observed in this investigation. Here the net adsorption capacity by spillover was defined as the number obtained by subtracting the physically

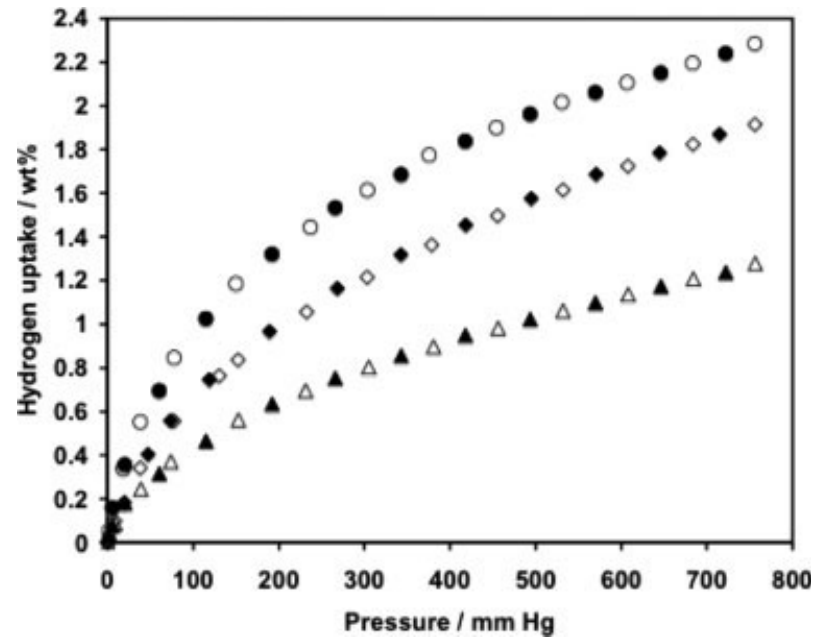

Figure 7. Hydrogen adsorption isotherms on COF-1 $(\triangle)$, HKUST-1 $(\bigcirc)$, and MIL-101 $(\diamond)$ at $77 \mathrm{~K}$.

Filled symbols indicate the desorption branches.

adsorbed hydrogen amount on the receptor (such as MIL101) from the total adsorption capacity on the bridged sample (bridged MIL-101).

As the hydrogen storage by spillover is by atomic hydrogen adsorption (not by condensation of hydrogen molecules), the surface adsorption sites of the material for hydrogen atoms adsorption should play an important role in determining the net storage capacity by spillover. A material with more and stronger surface adsorption sites for hydrogen atoms should have higher capacity for $\mathrm{H}_{2}$ via spillover. In this work, the heats of adsorption of $\mathrm{H}_{2}$ on the bridged samples were calculated by using the Clausius-Clapeyron equation from the $\mathrm{H}_{2}$ adsorption isotherms at 298 and $323 \mathrm{~K}$, as shown in Figure 11. The intercepts at zero pressure by extrapolating the isotherms at very low pressures in Figures 11a-c were the amounts of chemisorbed $\mathrm{H}_{2}$ on the Pt particles added to the samples. ${ }^{49}$ In this study, the contents of $\mathrm{Pt}$

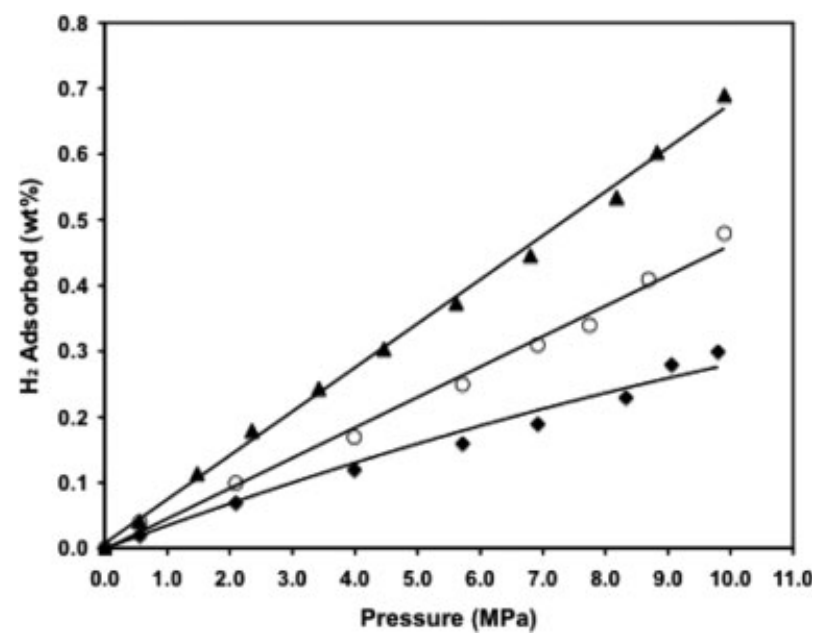

Figure 8. High-pressure hydrogen adsorption at $298 \mathrm{~K}$ for the COF-1 samples.

$\checkmark$ : pure COF-1; $\bigcirc$ : Pt/AC and COF-1 physical mixture; $\mathbf{\Delta}$ : COF-1-bridges-Pt/AC. 


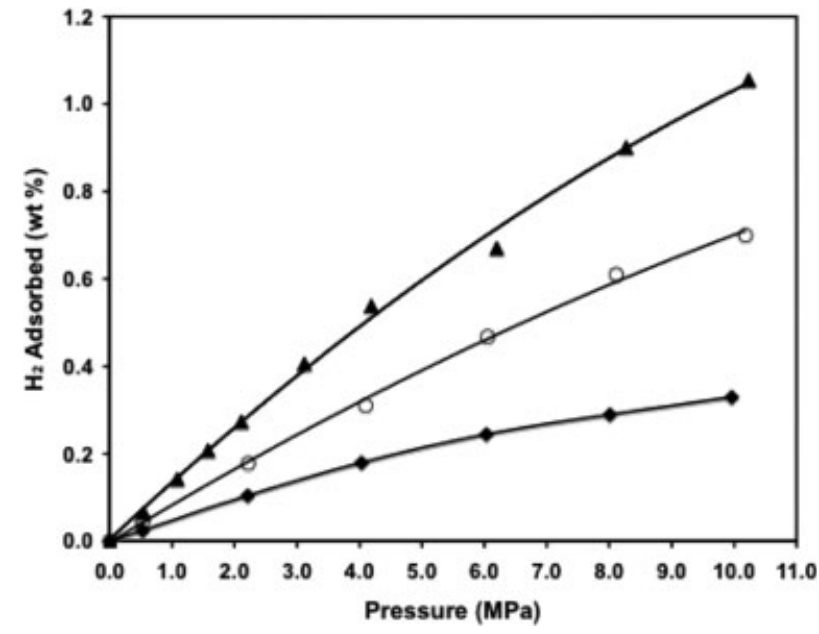

Figure 9. High-pressure hydrogen adsorption at $298 \mathrm{~K}$ for the HKUST-1 samples.

๑ : pure HKUST-1; O: Pt/AC and HKUST-1 physical mixture; $\boldsymbol{\Delta}$ : HKUST-1-bridges-Pt/AC.

added to the samples were all 0.5 wt \%. Assuming an adsorption of one $\mathrm{H}$ atom per surface $\mathrm{Pt}$ and a $100 \%$ dispersion of $\mathrm{Pt}$, the theoretical maximum amount of hydrogen expected to be adsorbed by the Pt added to the samples was calculated as $\sim 0.0026 \mathrm{wt} \%{ }^{50}$ The chemisorption amounts at zero pressure on the samples were all lower than the theoretical maximum value, corresponding to certain surface dispersions of Pt in the samples. It can be seen from Figure 11d that the heats of adsorption on the samples were quite high at low surface coverages (or low $\mathrm{H}_{2}$ adsorption amounts). This can be attributed to the strong adsorption of $\mathrm{H}_{2}$ on $\mathrm{Pt}$ metal, as well as the spiltover $\mathrm{H}$ on the strongest sites of the frameworks. The absolute value of heat of adsorption decreased sharply with adsorption amount for each sample, but leveled off at relatively high surface coverages. In this study, the predominant receptor for $\mathrm{H}$ atoms in the bridged sample was COF-1, or HKUST-1, or MIL-101. As a firstorder analysis and for simplicity, we take the heat of adsorption at relatively high $\mathrm{H}_{2}$ adsorption amount in Figure 11 as an indicator of the adsorption strength of hydrogen atoms on the surface of the receptor, i.e., COF-1, HKUST-1 or MIL101. Although different sites (such as C, O, and metal sites) on the COF or MOF material should have different interactions with hydrogen atom, it should be noted that ClausiusClapeyron equation always gives the average heats of adsorption. ${ }^{35}$ As shown in Figure $11 \mathrm{~d}$, the heats of adsorption at relatively high $\mathrm{H}_{2}$ adsorption amount (obtained at pressures $<1 \mathrm{~atm}$ ) on the bridged samples follow the order: bridged MIL-101 > bridged HKUST-1 > bridged COF-1.

In our work on the kinetics of spillover, ${ }^{35}$ a phenomenological equilibrium isotherm was derived for the spillover systems. The isotherm takes the form:

$$
q=\frac{k_{1} \sqrt{P_{H_{2}}}}{1+k_{2} \sqrt{P_{H_{2}}}-k_{3} \sqrt{P_{H_{2}}}}
$$

where $q$ is the amount adsorbed, $P_{\mathrm{H} 2}$ is the hydrogen pressure, and all three constants contain the Langmuir constant, i.e., as products of the Langmuir constant and other constants. In the pressure range of this work, the isotherm is far from saturation; thus, the second and third terms in the denominator are $<1$. As an approximation, the dependence of the amount adsorbed, $q$, on the heats of adsorption is approximately related through $k_{1}$. Thus, ${ }^{51}$

$$
q \propto e^{-\Delta H / R T}
$$

where $\Delta H$ is the heat of adsorption and $\mathrm{RT}$ has its usual meaning.

Figure 12 shows the net adsorption of $\mathrm{H}_{2}$ by spillover at $298 \mathrm{~K}$ and $10 \mathrm{MPa}$ vs. the heat of adsorption at relatively high $\mathrm{H}_{2}$ adsorption amount in Figure 11 for the bridged $\mathrm{COF}$ and MOF samples. As a comparison, the bridged IRMOF-8 sample that was previously reported was also included in Figure $12 .{ }^{34}$ For the four samples, the exponential correlation between the net hydrogen uptake by spillover and the heat of adsorption, via Eq. 2, was indeed observed. The results indicated the importance of the strength of the interaction between hydrogen atom and the surface of the material on the net hydrogen storage capacity by hydrogen spillover. The independence of the surface area and pore volume on the net $\mathrm{H}_{2}$ adsorption by spillover was also verified because IRMOF-8 has a much lower surface area and pore volume than MIL-101. ${ }^{33}$ Although the bridged IRMOF-8 had the highest $\mathrm{H}_{2}$ storage capacity, it would be unstable upon $\mathrm{H}_{2} \mathrm{O}$ adsorption because of the similar structure as MOF-5 (i.e., IRMOF-1). This would result in poor reproducibility of the samples and hence of the $\mathrm{H}_{2}$ storage capacity, which makes it difficult to use this material for practical hydrogen storage applications.

The simple analysis is only an approximation. The heats of adsorption of the spiltover hydrogen and the various sites of the MOF are not the same and are mostly higher than the leveled-off values shown in Figure $11 \mathrm{~d} .{ }^{35}$ More detailed analyses are needed to obtain a detailed understanding of the energetics of the spillover process.

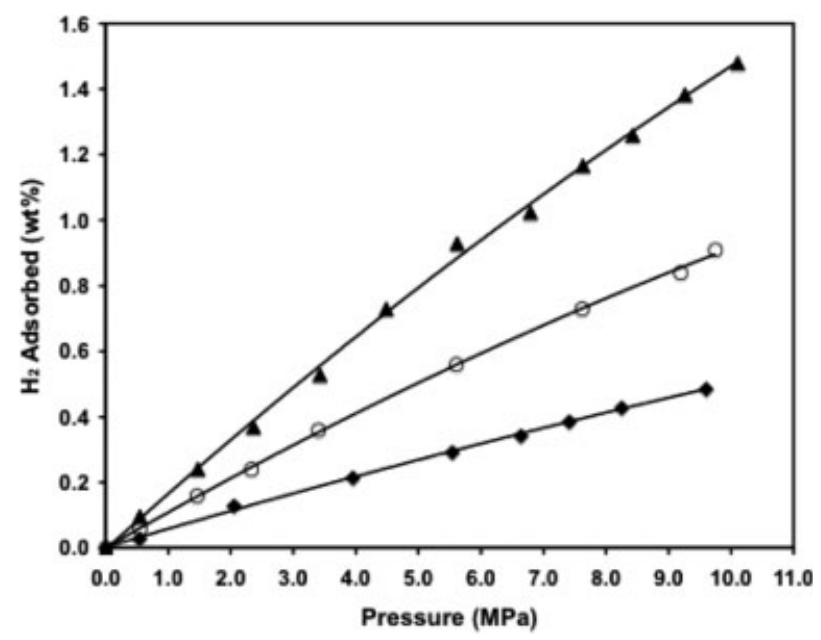

Figure 10. High-pressure hydrogen adsorption at $298 \mathrm{~K}$ for the MIL-101 samples.

$\checkmark$ : pure MIL-101; $\bigcirc$ : Pt/AC and MIL-101 physical mixture; $\boldsymbol{\Delta}$ : MIL-101-bridges-Pt/AC. 

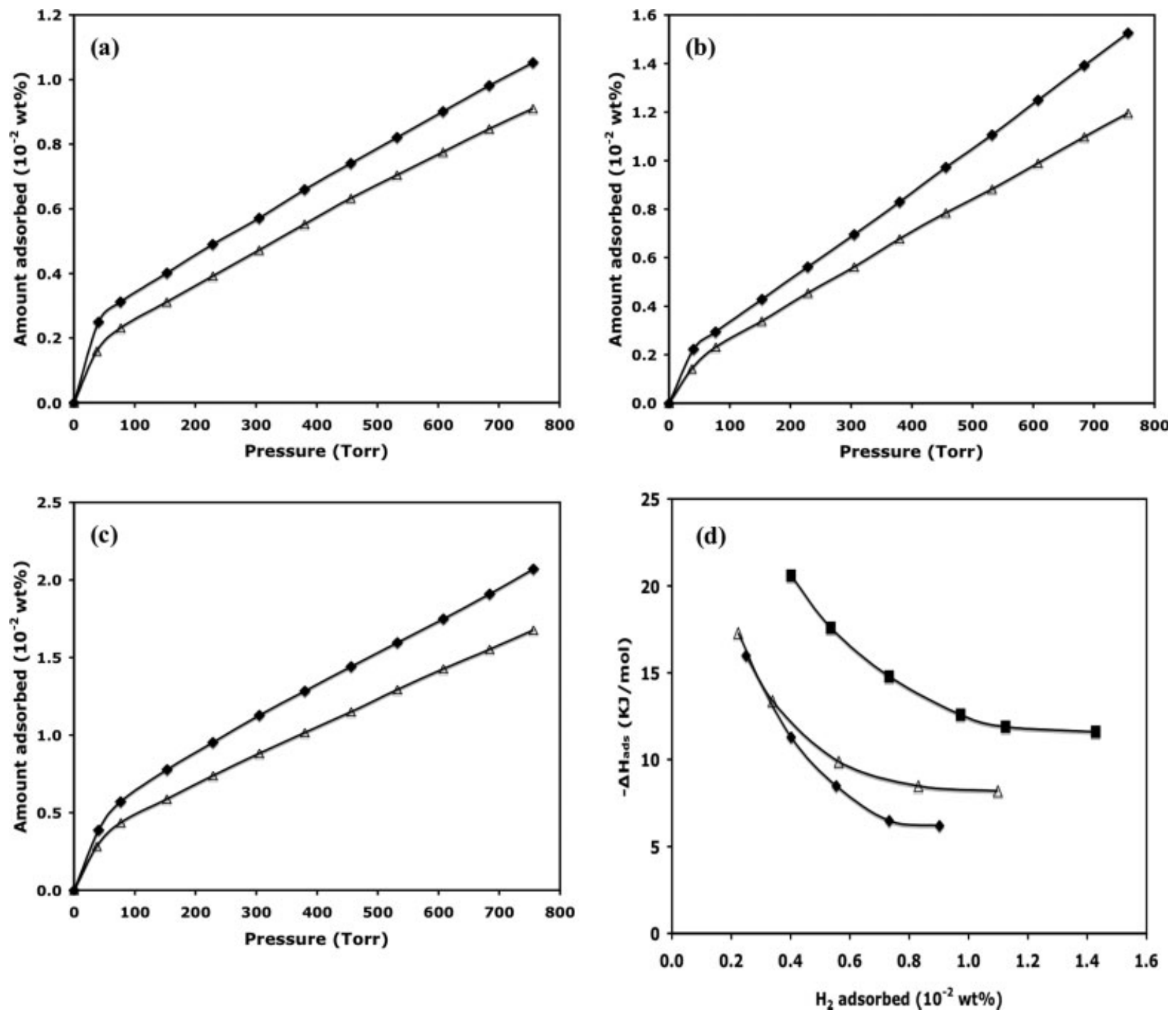

Figure 11. Low-pressure $\mathrm{H}_{2}$ equilibrium adsorption isotherms for (a) bridged COF-1, (b) bridged HKUST-1, and (c) bridged MIL-101 at $298 \mathrm{~K}(\diamond)$, and $323 \mathrm{~K}(\triangle)$, (d) calculated isosteric heats of adsorption of $\mathrm{H}_{2}$ for bridged COF-1 $(\diamond)$, bridged HKUST-1 $(\triangle)$, and bridged MIL-101 ( $\square$ ).

\section{Conclusions}

Three recently reported porous materials including covalent-organic framework COF-1, and metal-organic frameworks HKUST-1 and MIL-101 were synthesized and examined for low-pressure hydrogen adsorption at $77 \mathrm{~K}$ and highpressure hydrogen storage at room temperature. HKUST-1 exhibited the highest hydrogen uptake of $2.28 \mathrm{wt} \%$ at $77 \mathrm{~K}$ and $1 \mathrm{~atm}$ among the three materials. However, the highest hydrogen adsorption capacity at $10 \mathrm{MPa}$ and room temperature was obtained on the MIL-101 sample with the largest surface area and pore volume. The results suggested that the $\mathrm{H}_{2}$ uptake by physical adsorption on the $\mathrm{COF}$ and $\mathrm{MOF}$ materials at room temperature and high pressures correlated with the surface area and pore volume of the materials.

In addition, we have shown that hydrogen storage by hydrogen spillover is a promising method to enhance the storage capacity of the $\mathrm{COF}$ and MOF materials at room temperature. By bridged spillover, the hydrogen adsorption capacities on the COF-1, HKUST-1, and MIL-101 materials at $298 \mathrm{~K}$ and $10 \mathrm{MPa}$ have been enhanced by a factor of 2.6-3.2. The surface area and pore volume of the material were not the predominant factors on determining the net hydrogen adsorption capacity by spillover because the adsorption by spillover is by atomic hydrogen adsorption on the surface sites of the material. However, a correlation between the net hydrogen uptake by spillover and the heat of adsorption of the material has been found in an approximate analysis.

$\mathrm{H}_{2} \mathrm{O}$ vapor adsorption studies indicated that COF-1 was unstable upon $\mathrm{H}_{2} \mathrm{O}$ adsorption, while HKUST-1 and MIL101 were quite stable with $\mathrm{H}_{2} \mathrm{O}$ adsorbed. Our results suggest that MIL-101 could be a promising material for practical hydrogen storage application because of the high heat of adsorption for $\mathrm{H}_{2}$, the large surface area and pore volume and the high stability for $\mathrm{H}_{2} \mathrm{O}$. 


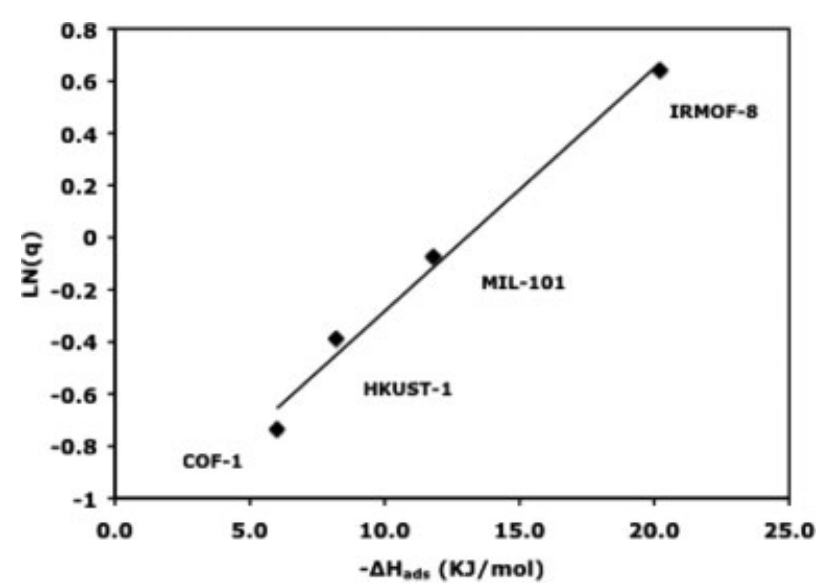

Figure 12. $L N(q)$ as a function of heat of adsorption for the COF, and MOF materials.

Here $q$ is the net adsorption amount by hydrogen spillover (wt \%).

This work is an initial effort to explore the correlations between the structural and surface characteristics and the $\mathrm{H}_{2}$ adsorption capacity of MOFs (or other materials with similar structures) by spillover. We are working on more MOFs, focusing on the most promising MOFs that have been structurally characterized. From these studies some useful criteria could be elucidated for the evaluation of new candidate MOFs for hydrogen storage by spillover.

\section{Acknowledgments}

The authors acknowledge the funding provided by the US Department of Energy's Office of Energy Efficiency and Renewable Energy within the Hydrogen Sorption Center of Excellence (HS CoE).

\section{Literature Cited}

1. Schlapbach L, Züttel A. Hydrogen-storage materials for mobile applications. Nature. 2001;414:353-358.

2. Hirscher $M$, Becher $M$. Hydrogen storage in carbon nanotubes. J Nanosci Nanotech. 2003;3:3-17.

3. Dillon AC, Heben MJ. Hydrogen storage using carbon adsorbents: past, present and future. Appl Phys A. 2001;72:133-142.

4. Yaghi OM, O'Keefee M, Ockwig NW, Chae HK, Eddaoui M, Kim J. Reticular synthesis and the design of new materials. Nature. 2003;423:705-714.

5. Rosi NL, Eckert J, Eddaoudi M, Vodak DT, Kim J, O'Keefee M, Yaghi OM. Hydrogen storage in microporous metal-organic frameworks. Science. 2003;300:1127-1129.

6. Suh MP, Ko JW, Choi HJ. A metal-organic bilayer open framework with a dynamic component: single-crystal-to-single-crystal transformations. J Am Chem Soc. 2002;124:10976-10977.

7. Snurr RQ, Hupp JT, Nguyen ST. Prospects for nanoporous metal-organic materials in advanced separations processes. AIChE J. 2004;50: 1090-1095.

8. Frost H, Duren T, Snurr RQ. Effects of surface area, free volume, and heat of adsorption on hydrogen uptake in metal-organic frameworks. J Phys Chem B. 2006;110:9565-9570.

9. Pan L, Sander MB, Huang XY, Li J, Smith M, Bittner E, Bockrath B, Johnson JK. Microporous metal organic materials: promising candidates as sorbents for hydrogen storage. J Am Chem Soc. 2004;126: 1308-1309.

10. Dinca M, Long JR. Strong $\mathrm{H}_{2}$ binding and selective gas adsorption within the microporous coordination solid $\mathrm{Mg}_{3}\left(\mathrm{O}_{2} \mathrm{C}-\mathrm{C}_{10} \mathrm{H}_{6}-\mathrm{CO}_{2}\right)_{3}$. J Am Chem Soc. 2005;127:9376-9377.
11. Zhao XB, Xiao B, Fletcher AJ, Thomas KM, Bradshaw D, Rosseinsky MJ. Hysteretic adsorption and desorption of hydrogen by nanoporous metal-organic frameworks. Science. 2004;306:1012-1015.

12. Rowsell JLC, Millward AR, Park KS, Yaghi OM. Hydrogen sorption in functionalized metal-organic frameworks. J Am Chem Soc. 2004; 126:5666-5667.

13. Dybtsev DN, Chun H, Yoon SH, Kim D, Kim K. Microporous manganese formate: a simple metal-organic porous material with high framework stability and highly selective gas sorption properties. J Am Chem Soc. 2004;126:32-33.

14. Kesanli B, Cui Y, Smith MR, Bittner EW, Bockrath BC, Lin W. Highly interpenetrated metal-organic frameworks for hydrogen storage. Angew Chem Int Ed. 2005;44:72-75.

15. Kubota Y, Takata M, Matsuda R, Kitaura R, Kitagawa S, Kato K, Sakata M, Kobayashi TC. Direct observation of hydrogen molecules adsorbed onto a microporous coordination polymer. Angew Chem Int Ed. 2005;44:920-923.

16. Férey G, Mellot-Draznieks C, Serre C, Millange F, Dutour J, Surblé S, Margiolaki I. A chromium terephthalate-based solid with unusually large pore volumes and surface area. Science. 2005;309:2040 2042.

17. Lin X, Jia JH, Zhao XB, Thomas KM, Blake AJ, Walker GS, Champness NR, Hubberstey P, Schroder M. High H-2 adsorption by coordination-framework materials. Angew Chem Int Ed. 2006;45: 7358-7364

18. Dinca M, Dailly A, Liu Y, Brown CM, Neumann DA, Long JR. Hydrogen storage in a microporous metal-organic framework with exposed $\mathrm{Mn}^{2+}$ coordination sites. J Am Chem Soc. 2006;128:1687616883.

19. Park H, Britten JF, Mueller U, Lee J, Li J, Parise JB. Synthesis, structure determination, and hydrogen sorption studies of new metalorganic frameworks using triazole and naphthalenedicarboxylic acid. Chem Mater. 2007;19:1302-1308.

20. Krungleviciute V, Lask K, Heroux L, Migone AD, Lee JY, Li J, Skoulidas A. Argon adsorption on $\mathrm{Cu}_{3}$ (Benzene-1,3,5-tricarboxylate $)_{2}\left(\mathrm{H}_{2} \mathrm{O}\right)_{3}$ metal-organic framework. Langmuir. 2007;23:3106-3109.

21. Jiang JW, Sandler SI. Monte Carlo simulation for the adsorption and separation of linear and branched alkanes in IRMOF-1. Langmuir. 2006;22:5702-5707.

22. Hu X, Trudeau M, Antonelli DM. Hydrogen storage in microporous titanium oxides reduced by early transition metal organometallic sandwich compounds. Chem Mater. 2007;19:1388-1395.

23. Park H, Moureau DM, Parise JB. Hydrothermal synthesis and structural characterization of novel $\mathrm{Zn}$-Triazole-benzenedicarboxylate frameworks. Chem Mater. 2006;18:525-531.

24. Perles J, Iglesias M, Martin-Luengo MA, Monge MA, Ruiz-Valero C, Snejko N. Hydrothermal synthesis and structural characterization of novel $\mathrm{Zn}$-triazole-benzenedicarboxylate frameworks. Chem Mater. 2006; 17:5837-5842.

25. Seayad AM, Antonelli DM. Recent advances in hydrogen storage in metal-containing inorganic nanostructures and related materials. $A d v$ Mater. 2004:16:765-777.

26. Prestipino C, Regli L, Vitillo JG, Bonino F, Damin A, Lamberti C, Zecchina A, Solari PL, Kongshaug KO, Bordiga S. Local structure of framework $\mathrm{Cu}$ (II) in HKUST-1 metallorganic framework: spectroscopic characterization upon activation and interaction with adsorbates. Chem Mater. 2006;18:1337-1346.

27. Wong-Foy AG, Matzger AJ, Yaghi OM. Exceptional H-2 saturation uptake in microporous metal-organic frameworks. $\mathrm{J}$ Am Chem Soc. 2006;128:3494-3495.

28. Latroche M, Surble S, Serre C, Mellot-Draznieks C, Llewellyn PL, Lee JH, Chang JS, Jhung SH, Ferey G. Hydrogen storage in the giant-pore metal-organic frameworks MIL-100 and MIL-101. Angew Chem Int Ed. 2006;45:8227-8231.

29. Rowsell JLC, Yaghi OM. Effects of functionalization, catenation, and variation of the metal oxide and organic linking units on the low-pressure hydrogen adsorption properties of metal-organic frameworks. J Am Chem Soc. 2006;128:1304-1315.

30. Kaye SS, Long JR. Hydrogen storage in the dehydrated Prussian blue analogues $\mathrm{M}_{3}\left[\mathrm{Co}(\mathrm{CN})_{6}\right]_{2}(\mathrm{M}=\mathrm{Mn}, \mathrm{Fe}, \mathrm{Co}, \mathrm{Ni}, \mathrm{Cu}, \mathrm{Zn}) . J \mathrm{Am}$ Chem Soc. 2005;127:6506-6507.

31. Panella B, Hirscher M, Putter H, Muller U. Hydrogen adsorption in metal-organic frameworks: $\mathrm{Cu}-\mathrm{MOF}$ and $\mathrm{Zn}-\mathrm{MOFs}$ compared. $A d v$ Funct Mater. 2006;16:520-524. 
32. Yang RT, Li YW, Qi GS, Lachawiec AJ. U.S. Patent applications Serial No. 2006;11:442898 and Serial No. 2007;11:820954.

33. Li YW, Yang RT. Significantly enhanced hydrogen storage in metal-organic frameworks via spillover. J Am Chem Soc. 2006; 128:726-727.

34. Li YW, Yang RT. Hydrogen storage in metal-organic frameworks by bridged hydrogen spillover. J Am Chem Soc. 2006;128:81368137.

35. Li YW, Yang FH, Yang RT. Kinetics and mechanistic model for hydrogen spillover on bridged metal-organic frameworks. $J$ Phys Chem C. 2007;111:3405-3411.

36. Yang RT. Hydrogen storage by alkali-doped carbon nanotubes-revisited. Carbon. 2000;38:623-626.

37. Panella B, Hirscher M. Hydrogen physisorption in metal-organic porous crystals. Adv Mater. 2005;17:538-541.

38. Huang LM, Wang HT, Chen JX, Wang ZB, Sun JY, Zhao DY, Yan YS. Synthesis, morphology control, and properties of porous metalorganic coordination polymers. Microporous Mesoporous Mater. 2003;58:105-114.

39. Cote AP, Benin AI, Ockwig NW, O'Keeffe M, Matzger AJ, Yaghi OM. Porous, crystalline, covalent organic frameworks. Science. 2005; 310:1166-1170.

40. Chui SSY; Lo SMF, Charmant JPH, Orpen AG, Williams ID. A chemically functionalizable nanoporous material $\left[\mathrm{Cu}_{3}(\mathrm{TMA})_{2}\left(\mathrm{H}_{2} \mathrm{O}\right)_{3}\right]_{\mathrm{n}}$. Science. 1999;283:1148-1150.

41. Xiao B, Wheatley PS, Zhao XB, Fletcher AJ, Fox S, Rossi AG, Megson IL, Bordiga S, Regli L, Thomas KM, Morris RE. Highcapacity hydrogen and nitric oxide adsorption and storage in a metal-organic framework. J Am Chem Soc. 2007;129:1203-1209.
42. Li YW, Yang, RT. Hydrogen storage in low silica type $\mathrm{X}$ zeolites. J Phys Chem B. 2006;110:17175-17181.

43. Lachawiec AJ, Qi GS, Yang RT. Hydrogen storage in nanostructured carbons by spillover: bridge-building enhancement. Langmuir. 2005;21:11418-11424.

44. Jhuang SH, Lee JH, Yoon JW, Serre C, Ferey G, Chang JS. Microwave synthesis of chromium terephthalate MIL-101 and its benzene sorption ability. Adv Mater. 2007;19:121-124.

45. Dathe H, Peringer E, Roberts V, Jentys A, Lercher JA. Metal organic frameworks based on $\mathrm{Cu}^{2+}$ and benzene-1,3,5-tricarboxylate as host for $\mathrm{SO}_{2}$ trapping agents. $C$ R Chemie. 2005;8:753-763.

46. Lee JY, Li J, Jagiello J. Gas sorption properties of microporous metal organic frameworks. J Solid State Chem. 2005;178:25272532.

47. Ferey G. A chromium terephthalate-based solid with unusually large pore volumes and surface area. Science. 2005;310:11191119.

48. Conner WC, Falconer JL. Spillover in heterogeneous catalysis. Chem Rev. 1995;95:759-788.

49. Benson JE, Boudart M. Hydrogen-oxygen titration method for the measurement of supported platinum surface areas. $J$ Catal. 1965;4:704-710.

50. Li YW, Yang RT. Hydrogen storage on platinum nanoparticles doped on super-activated carbon. J Phys Chem C. 2007;111:1108611094.

51. Yang RT. Gas Separation by Adsorption Processes. London: Butterworth, 1987. Chapter 2.

Manuscript received Aug. 8, 2007, and revision received Sept. 25, 2007. 